\title{
Properties Evaluation of Injection Moulded Gas and Water Atomised 316L Stainless Steel Powder
}

\author{
Mohd Afian Omar ${ }^{1 *}$, Istikamah Subuki ${ }^{2}$ \\ ${ }^{1}$ SIRIM Bhd, Lot 34, Jln Hi Tech 2/3, Kulim Hi Tech Park, 09000 Kulim, Kedah, Malaysia \\ ${ }^{2}$ Faculty of Chemical Engineering, UiTM Shah Alam, 40450 Shah Alam Selangor, Malaysia
}

\begin{abstract}
DOI: $10.36348 /$ sjet.2020.v05i08.003 $\quad$ | Received: 09.08 .2020 | Accepted: 17.08 .2020 | Published: 30.08 .2020
*Corresponding author: Mohd Afian Omar
\end{abstract}

\section{Abstract}

This paper investigate the characteristics important to injection moulding via rheological behaviour, injection moulding, debinding and sintering process of water and gas atomised 316L stainless steel powder using new locally based binder system; palm stearin. The critical powder loading for injection moulding were $65 \mathrm{vol} \%$ and $62 \mathrm{vol} \%$ for gas and water atomised respectively. The gas atomised powder proves easier to mold because of a low interparticle friction and high packing density. In contrast, the water atomised powder has high viscosity of the injection moulding feedstock, high interparticle friction and a low packing density that interfere with injection moulding. Binder debinding was performed using solvent and thermal method. After debinding the samples were sintered at $1360^{\circ} \mathrm{C}$ using a high temperature vacuum furnace. Results indicate that water atomised powder could be sintered to $95 \%$ of theoretical density, while gas atomised powders could be sintered to near full density.

Keywords: Metal injection moulding, gas atomised, water atomised, debinding, sintering.

Copyright @ 2020: This is an open-access article distributed under the terms of the Creative Commons Attribution license which permits unrestricted use, distribution, and reproduction in any medium for non-commercial use (NonCommercial, or CC-BY-NC) provided the original author and source are credited.

\section{INTRODUCTION}

This document is template. The PIM is an attractive process for the production of complicated of near-net shape components of high performance materials. The PIM process is composed of four sequential steps; mixing of the powder with organic binder, injection moulding, debinding (binder removal) and sintering [1]. Over $50 \%$ of the injection moulded and sintered components are made from stainless steel composition. Besides dimensional precision, the requirement for stainless steel components include strength, ductility, hardness, corrosion resistance and aesthetics [2].

It has been established that gas atomised stainless steel powder is generally used due to their spherical in shape that lead to high packing density and associated rheology. However, this material are expensive and low interparticle friction (which affect component shape retention) that susceptible to shape distortion in processing [1-4]. Water atomised powder is typically economical and has less spherical particle in shape, which creates a high interparticle friction, resulting in improve shape retention $[5,6]$. However, it has a lower packing density and the texture surface increased the MIM feedstock viscosity [6]. Moreover, the water atomised powders are use comes with a penalty of lower solids loading and sintered density, with a corresponding degradation in the mechanical and corrosion properties. Studies reveal that injection moulded and sintered components using water atomised $316 \mathrm{~L}$ stainless steel powders have a residual porosity of 3-5\% for similar particle characteristics and sintering conditions as that of gas atomised powders [7]. Most investigation of the water atomised powders via injection moulding can achieved $97 \%$ of theoretical density by using paraffin wax, polypropylene and stearic acid binder system [5-9].

Istikamah et al., [10] reported that gas atomised $316 \mathrm{~L}$ stainless steel powder was homogenous mixed with a new developed binder system; palm stearin (PS) and polyethylene (PE) and can be injection moulded and the samples were successfully sintered without any defects on the sintered parts and the density are near to full density. The advantages of this biopolymer binder; PS includes local natural resources and environmental friendly. Besides that, this binder system has proven can shorten the overall debinding process by performing solvent extraction technique [11]. 
Due to these considerations, the purpose of this study was to investigate the possibility of palm stearin as a based binder system and compare the whole process of injection moulding in the gas and water atomised $316 \mathrm{~L}$ stainless steel with the aim of reduces the cost of manufacturing.

\section{MATERIALS AND METHOD}

The powders have similar particle size and particle size distribution. Morphology of the powders observed using SEM are given in Fig 1(a) and (b). The powder loading for the gas and water atomised powder feedstock was 65 and $62 \mathrm{vol} \%$ [7] respectively. The low packing density of water atomised powder necessitate an excess of powder which require more sintering shrinkage to attain a high final density. In this investigation, palm stearin was used as based binder system with the composition was 70 wt. \% of palm stearin (PS) and $30 \mathrm{wt} \%$ of polyethylene (PE) [10].
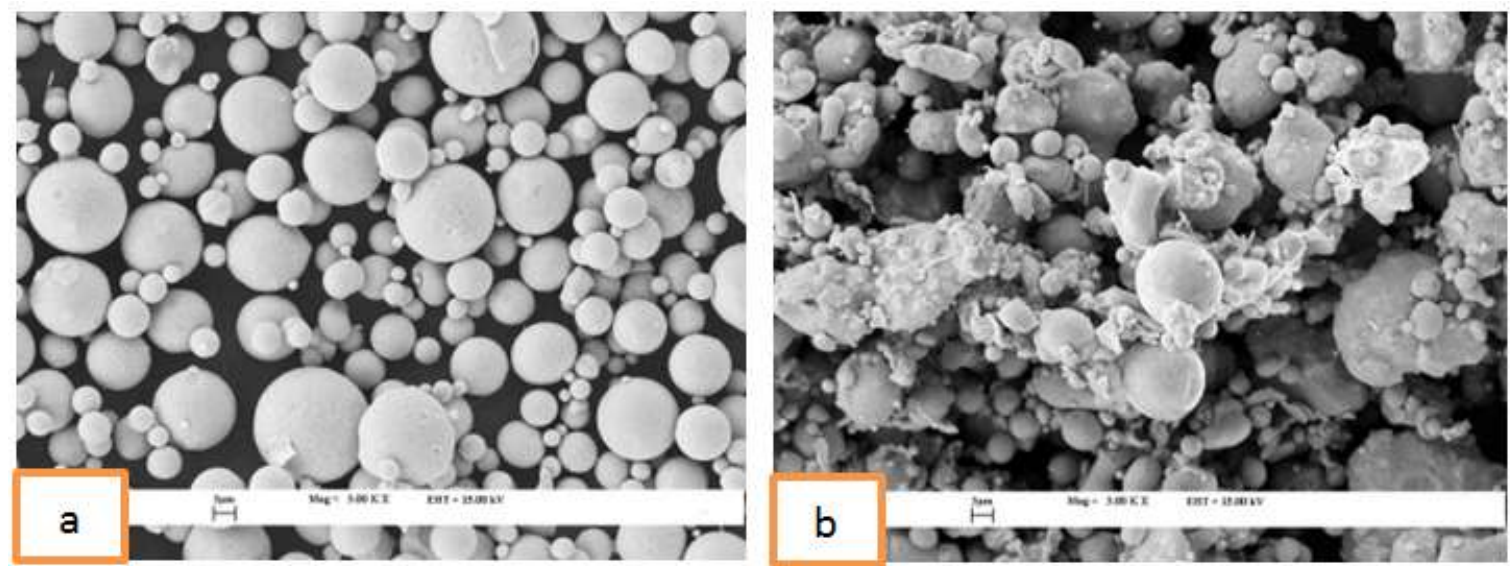

Fig-1: Scanning electron micrograph of 316 $\mathrm{L}$ powder; (a) gas atomised and (b) water atomised

Mixing process of the powder and the binder system was carried out using a sigma-blade mixer at the temperature of $160^{\circ} \mathrm{C}$ and was hold for 2 hours. The feedstock was then granulated in pellet form in order to be fed easily in an injection moulding machine. The rheological characteristics of the feedstock was study using a Shimadzu CFT-500D Capillary Rheometer. During the capillary rheometer test, the feedstock was forcibly extruded through a small cylindrical orifice with a $1.0 \mathrm{~mm}$ diameter and $10 \mathrm{~mm}$ length $(\mathrm{L} / \mathrm{D}=10)$. The test were conducted at 130,150 and $160^{\circ} \mathrm{C}$.The tensile specimen was prepared using a vertical injection moulding model MCP HEK-GMBH. During moulding, the temperature and injection pressure were adjusted until the optimum conditions was obtained. The green parts present very good homogeneity as deduced from the SEM observation and from green density values.

The binder of palm stearin was then removed by means of solvent extraction by immersing the samples in an n-heptane solution for 5 hours at the temperature of $60^{\circ} \mathrm{C}$ [10]. The parts which had undergone solvent extraction were subjected to a thermal debinding where the organic binder, polyethylene (PE) was completely removed. At this process, the parts were heated to $450^{\circ} \mathrm{C}$ with heating rate of $3^{\circ} \mathrm{C} / \mathrm{min}$ and holding time of 2 hours. Sintering process was carried out using a high temperature vacuum furnace and the specimens were sintered at $1360^{\circ} \mathrm{C}$ with heating rate of $5^{\circ} \mathrm{C} / \mathrm{min}$. All sintered samples were characterized physically and mechanically in order to evaluate the possibility of high packing density of sintered specimen by using $316 \mathrm{~L}$ water atomised mixed with locally binder system (PS). Tensile test was carried out using an UTS machine, while hardness test was carried out using a Vickers micro-hardness tester with the applied load of $100 \mathrm{gf}$. The density of sintered parts was measured using Archimedes method.

\section{RESULTS AND DISCUSSION Rheological Characterization}

In MIM, the rheological properties are important for the injection molding step as it concerns the flow of the feedstock during injection moulding. Rheological analysis can be used to quantify the stability of the feedstock during the moulding process [3]. There is a range of conditions over which the MIM processing is most viable. In this range, the mixture exhibits pseudoplastic flow where the viscosity decrease with increasing shear rate and this can help to reduce the required temperature and pressure for successful moulding [2-4]. Pseudoplastic flow behaviour eases mold filling, minimize jetting and help to retain the shape of the molded part. 


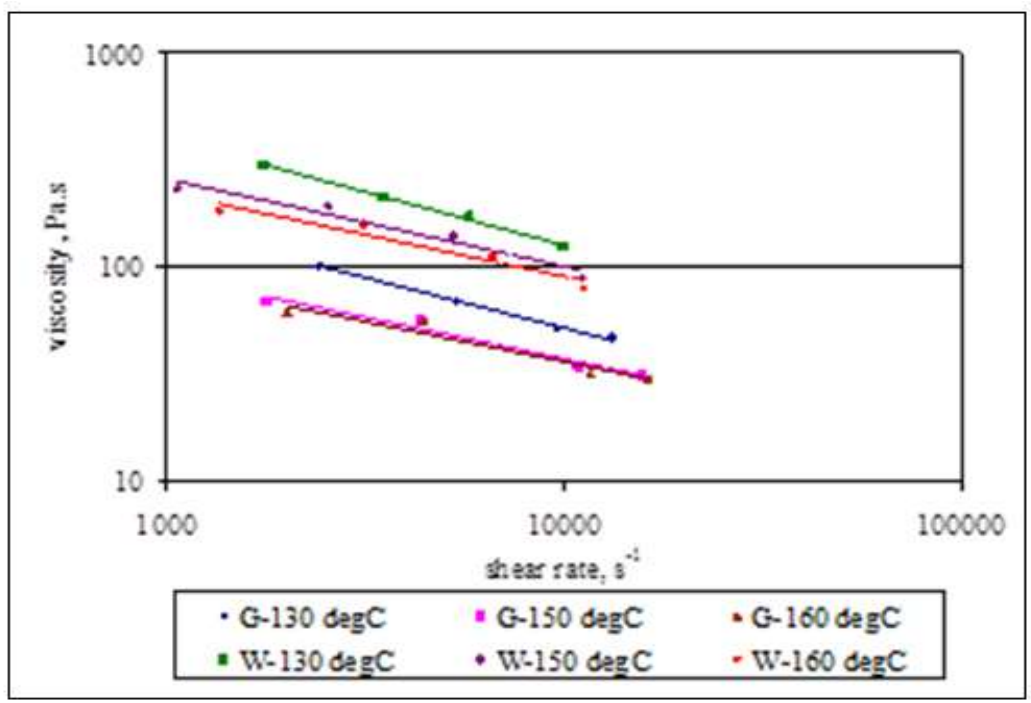

Fig-2: Viscosity-shear rate of MIM feedstock of gas and atomised powder

The rheological results of the feedstock made with gas and water atomised powder are shown in Fig2. All the feedstock viscosity decreased with increasing shear rate and this behaviour is generally called pseudoplastic behaviour that suitable for metal injection moulding process. The non spherical shape of water atomised gave the highest viscosity in all temperature study. Although the viscosity is more than that of the spherical gas powder, the water atomised exhibit satisfactory behaviour for further injection moulding test.
The relation of viscosity $(\eta)$ and shear rate ( $\gamma$ ) can be expressed from the Arrhenius equation as in (1).

$$
\eta=k \gamma^{n-1}
$$

The value of $n$ indicates the degree of shear sensitivity and pseudoplasticity. The lower value of $n$, the more quickly the viscosity of the feedstock changes with shear rate. In turn the higher value of $n$ indicates the better the rheological stability of the feedstock. Table-2 list the value of shear sensitivity of the feedstock prepared. It clearly shows that all data give relatively the same value of $n$.

Table-1: Data of shear sensitivity $(n)$ for gas and water atomised powder at different temperature

\begin{tabular}{|l|l|l|l|}
\hline Temperature & $\mathbf{1 3 0}^{\mathbf{}} \mathbf{C}$ & $\mathbf{1 5 0}^{\mathbf{}} \mathbf{C}$ & $\mathbf{1 6 0}^{\mathbf{}} \mathbf{C}$ \\
\hline Water atomised powder & 0.5016 & 0.591 & 0.6095 \\
Gas atomised powder & 0.5309 & 0.6119 & 0.6241 \\
\hline
\end{tabular}

Their viscosity is also observed to be temperature sensitive. As temperature increase, there is noticeable decrease in the feedstock's viscosity. This phenomena is mainly due to (a) a decrease in the powder volume caused by the larger expansion of the binder when heat is introduced; and (b) disentanglement of the molecular chain when more heat is distributed to fluctuate the random molecular structure [2]. With a shear rate varying from 100 to $10000 \mathrm{~s}^{-1}$, the viscosity of the feedstock falls below $1000 \mathrm{~Pa} \mathrm{~s}$. Thus, the feedstock is suitable for injection moulding.

Concerning the gas and water atomised $316 \mathrm{~L}$ SS powders, there is not much difference in their rheological behaviour because their particle sizes and shapes are not so different

\section{Injection Moulding}

After several trials and error, the feedstock was successfully injection moulded at the nozzle temperature of $230^{\circ} \mathrm{C}$ and $210^{\circ} \mathrm{C}$ for gas and water atomised respectively and injection pressure of $30 \mathrm{MPa}$. The moulding temperature used during the study can be considered as much higher as compared to other reports, which commonly used at the range of $100^{\circ} \mathrm{C}$ to $200^{\circ} \mathrm{C}$ [7-9]. Higher temperature is needed to compensate the viscosity of the feedstock during injection. Nevertheless, during the injection, all injection parts were fairly good and free from normal defects such as short shot, flashes at the parting surface and binder separation.

Figure-3 is a typical fracture surface of a green part show that a good homogeneity was achieved for gas and water atomised 316L stainless steel. Spherical and irregular shape of powders can be seen in these fractures of water atomised green parts. Green densities of moulded samples of gas and water atomised powder were approximately 5.2 and $5.0 \mathrm{~g} / \mathrm{cm}^{3}$ respectively. Green density of moulded specimen of water atomised 
powder was approximately $5.0 \mathrm{~g} / \mathrm{cm}^{3}$ which is slightly lower as compared with the specimen made with gas atomised $\left(5.2 \mathrm{~g} / \mathrm{cm}^{3}\right)$. The lower green density of water atomised specimen is associated with poor packing property of the powder.
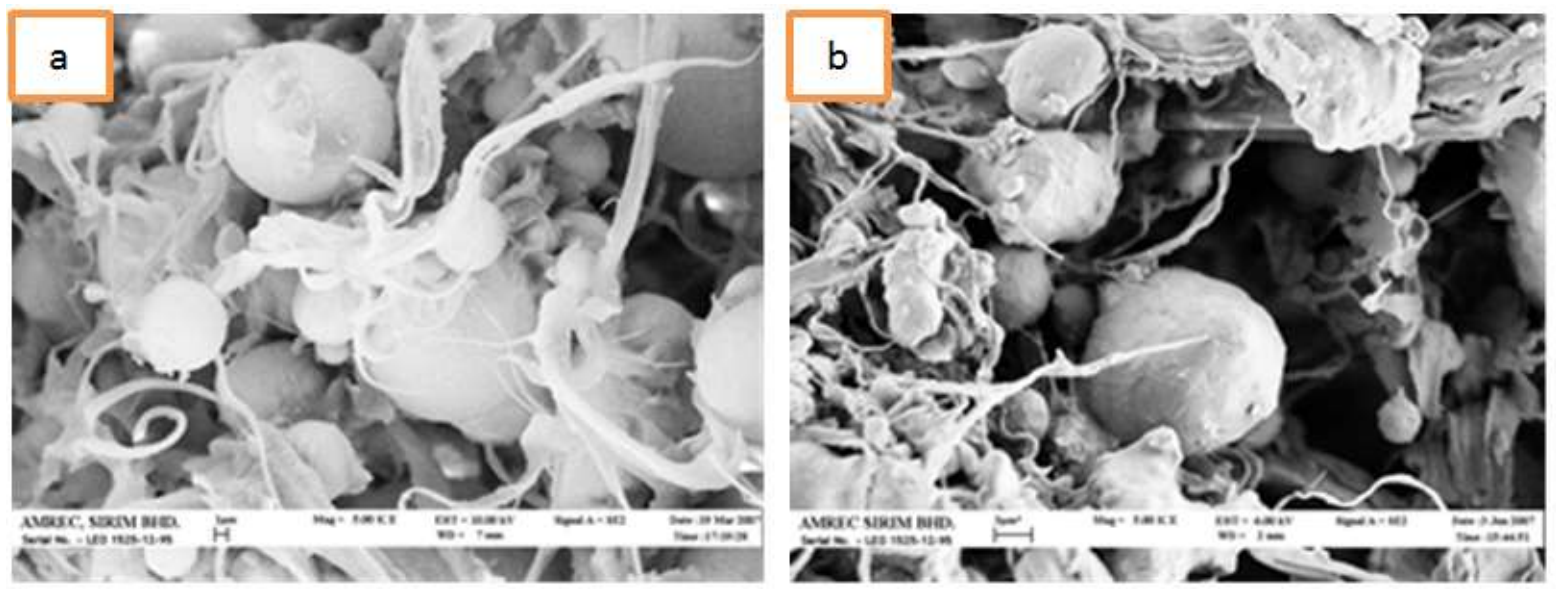

Fig-3: SEM shows the distribution of the PS/PE binder system on fractured injected parts; (a) gas atomized and (b) water atomized

Low tap density as a measure of packing shows that the packing density of water atomised specimen $\left(4.05 \mathrm{~g} / \mathrm{cm}^{3} \sim 54 \%\right.$ of MIM standard density of $7.6 \mathrm{~g} / \mathrm{cm}^{3}$ ) (EPSON ATMIX) is considerably less than that of gas atomized specimen $\left(5.04 \mathrm{~g} / \mathrm{cm}^{3} \sim 64 \%\right.$ of MIM standard density of $7.9 \mathrm{~g} / \mathrm{cm}^{3}$ ) (ANVAL).

However these values are considered to be adequate for MIM specimens. Even though water atomised specimen has a lower green density, due to a better interlocking mechanism, it shows a satisfactory green strength, which is $4.12 \mathrm{MPa}$ almost $0.6 \mathrm{MPa}$ better than gas atomised specimen.

\section{Debinding Process}

For safe and rapid binder removal with minimum possibility of cracks and blister formation, solvent debinding followed by thermal debinding was used. The binder chosen includes the lower stability components of palm stearin which are removed in early stage of debinding and generate pore channels inside of the part that allow gaseous product of degradation of remaining binder harmlessly diffuse out of the structure while polyethylene has a function of holding particles together during and after extraction lower stability components to maintain the part shape.

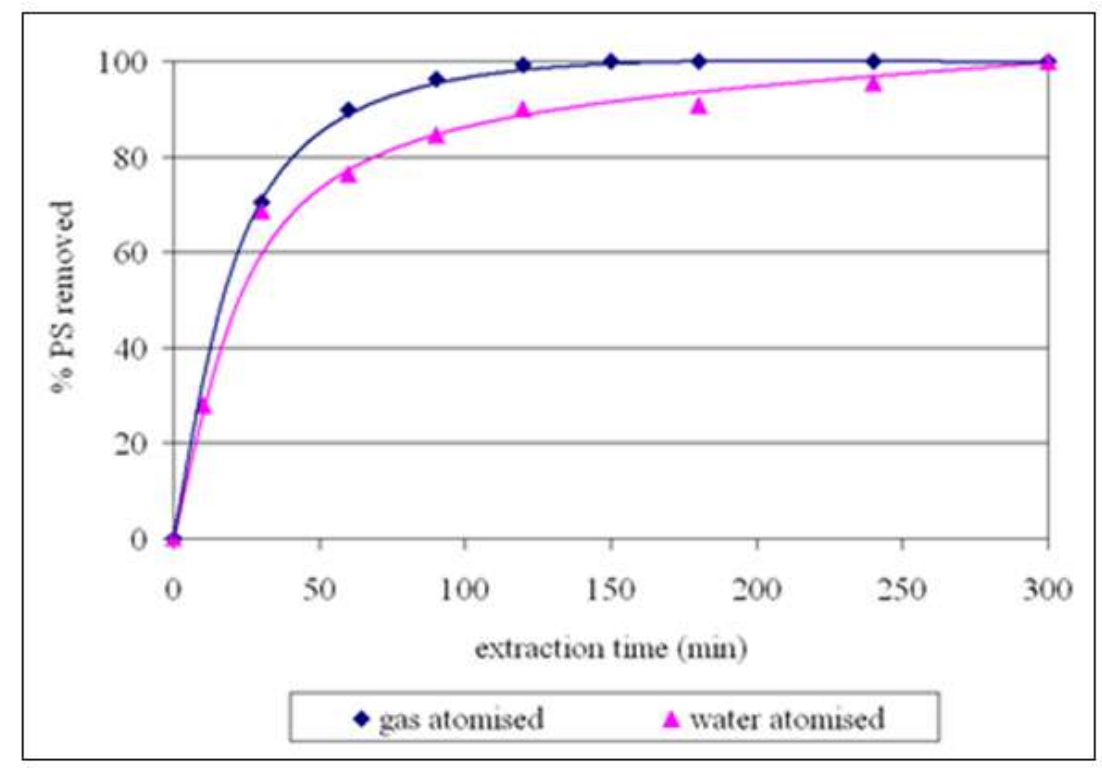

Fig-4: Effect of temperature during solvent extraction process in heptane

The time of immersion of PS water atomised powder specimens in heptane is much lower than that of gas atomised powder specimens as shown in Figure-4, which is due to the different powder characteristics. The PS content was completely removed after being immersed in heptane for 300 minutes for water atomised specimens while only for 180 minutes for gas atomised specimens. The irregular particles of water atomised specimens retard the PS to diffuse out, which lead to slow debinding process. 


\section{Sintering Process}

\section{Physical Properties}

In this stage, temperature increase from $30^{\circ} \mathrm{C}$ to the sintering temperature at $1360^{\circ} \mathrm{C}$ with the rate of $5^{\circ} \mathrm{C} / \mathrm{min}$ under vacuum atmosphere and held at the temperature for 1 hour. After sintering, it was not observed any signs of defects such as blister and crack in the specimens.

It was observed that the density of the sintered parts is 7.86 and $7.5 \mathrm{~g} / \mathrm{cm}^{3}$ for gas and water atomised respectively. As expected the higher green density of gas atomised sample (spherical shape) exhibit good packing that give near to full density of sintered specimen. Nevertheless, the water atomised (spherical and irregular shape) exhibit poor packing density which incline low green and sintered density of specimen which is about $95 \%$ of theoretical density. The lower packing density of the water atomised resulted in a lower final density. Cai and German [7] who study the metal injection moulding of water atomised $316 \mathrm{~L}$ stainless steel with paraffin wax, polypropylene and stearic acid as a binder system by using 62 vol\% reported that the sintered density of the specimen after sintering at $1370^{\circ} \mathrm{C}$ in Hidrogen was $96 \%$. The density was increased to $98 \%$ as the sintering temperature increase to $1390^{\circ} \mathrm{C}$ [5]. So, for achieving a higher density and also better mechanical properties of the sintered parts, some of the processing conditions should be optimized.

Shrinkages were calculated by comparing the tensile sample dimensions at each stage to that of the green specimen as shown in Figure-5. The dimensions measured were the length, which was parallel to the melt flow; width, perpendicular to the melt flow and thickness, parallel to the mould opening direction. Figure 4.80 shows the comparison of the shrinkage of specimen of $316 \mathrm{~L}$ water atomised powder with the gas atomised powder of PSPE65-4 using the same composition of binder feedstock.

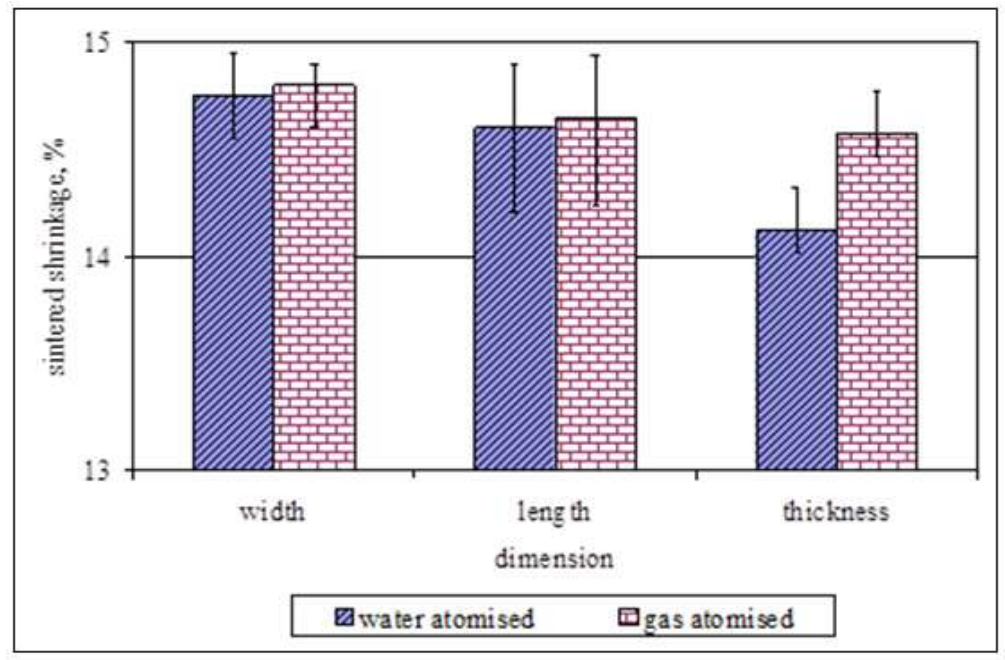

Fig-5: Percentage of shrinkage after sintered at $1360^{\circ} \mathrm{C}$

It shows that the shrinkage were approximately $14 \%$ at all dimensions. The water atomised powder exhibits a similar shrinkage tendency compared to the gas atomised. High sintered density of gas atomised, approximately $99 \%$ resulted in high sintering shrinkage as compared with water atomised powder. Irregular powders have a higher surface area per unit volume that accelerates sintering [2]. During sintering process, at the initial stage the pore structure is interconnected and irregular in shape for both spherical powder and nonspherical powder. Further sintering process, the changes of neck size, shrinkage and porosity is slightly different. As water atomised powder used has rounded and irregular shape, there are not much different in shrinkage since it used the same powder loading.

\section{Microstructure Analysis}

Figure-6 shows the sintered as polished microstructure of samples made from water and gas atomised powder. The microstructure shows that the pores were isolated either in the grain interior or at the grain boundaries in the parts containing porosity of up to $7 \%$. The high porosity resulted in low density of $316 \mathrm{~L}$ SS water atomised specimens. Large pores were located along the grain boundaries and they will act to increase the crack length to result in lower tensile strength of the sintered specimen. Compared to gas atomized powder, the porosity is less than $4 \%$. 

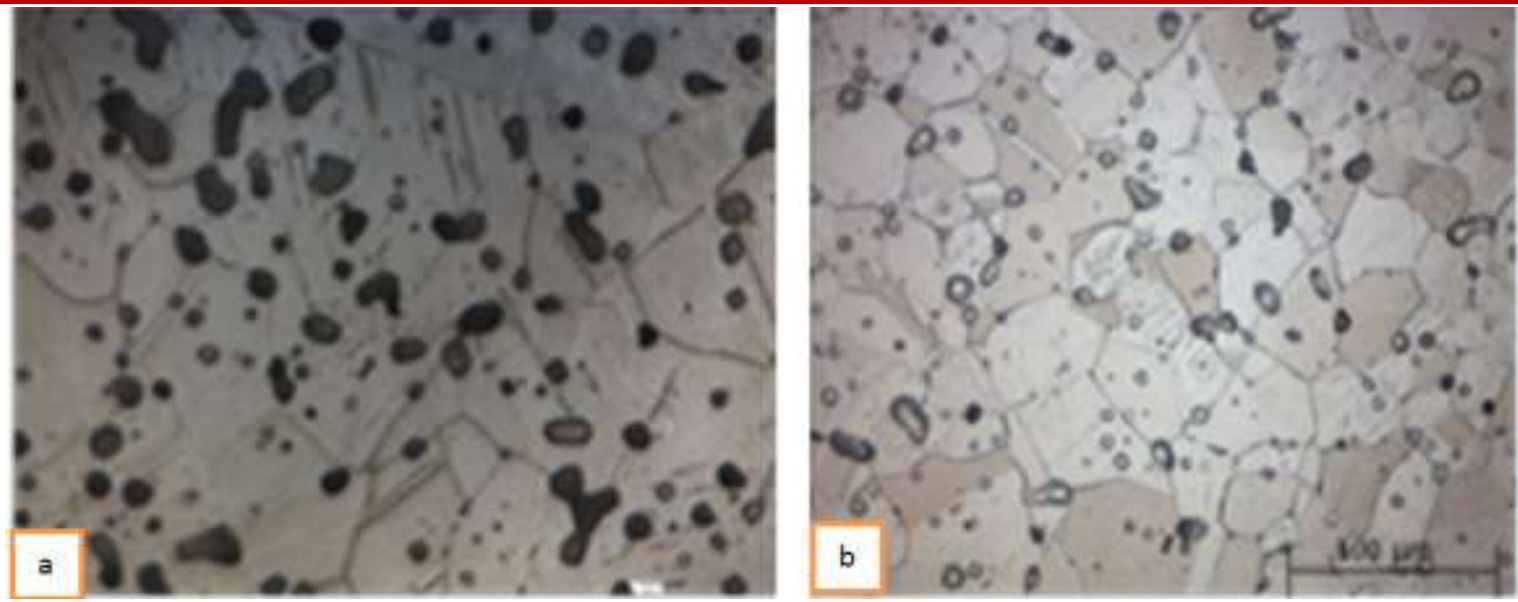

Fig-6: The microstructure of water and gas atomized powder after sintered at $1360^{\circ} \mathrm{C}$

\section{Mechanical Properties}

Table-2 shows the comparison of mechanical properties of experimental data with MPIF Standard 35. From the results obtained, it can be concluded that the sintered specimen of injection moulding of water atomised $316 \mathrm{~L}$ using palm stearin based binder system was nearly achieving the MPIF Standard 35 but more study considered different temperature, cycle time and atmosphere in order to achieved high mechanical properties of sintered specimen.

Table-2: Mechanical properties of tensile specimen sintered at $1360^{\circ} \mathrm{C}$ in vacuum

\begin{tabular}{|l|l|l|l|}
\hline Properties & Gas Atomised & Water Atomised & MPIF Standard 35 \\
\hline Hardness (HV) & $230 \pm 2$ & $222 \pm 3$ & $>200$ \\
\hline Tensile Strength (MPa) & $530 \pm 2$ & $443 \pm 1$ & $\geq 448$ \\
\hline Elongation at break (\%) & $45 \pm 3$ & $41 \pm 2$ & $\geq 40$ \\
\hline
\end{tabular}

\section{REFERENCES}

1. German, R. M. (1990). Powder Injection Moulding. Metal Powder Industries Federation, Princeton, New Jersey.

2. German, R. M., \& Bose, A. (1997). Injection Molding of Metals and Ceramic, Metal Powder Industries Federation, Princeton, New Jersey.

3. Huang, B., Liang, S., \& Qu, X. (2003). The Rheological of Metal Injection Molding. Journal of Material Processing Technology. 137, 132-137.

4. Liu, Z. Y., Loh, N. H., Tor, S. B., \& Khor, K. A. (2003). Characterization of powder injection moulding feedstock, Material Characterization. 49, 313-320.

5. Suri, P., Koseski, R. P., \& German, R. M. (2005). Microstructure evolution of injection moulded gas and water atomised $316 \mathrm{~L}$ stainless steel powder during sintering. Material Science and Engineering A. 402, 341-348.

6. German, R. M., \& Kubish, D. (1993). Evaluation of Injection Moulded 17-4 PH Stainless Steel Using Water Atomised Powder. The International Journal of Powder Metallurgy, 29(1):47-61.
7. Cai, L., \& German, R. M. (1995). Powder Injection Moulding Using Water Atomised 316L Stainless Steel. The international Journal of Powder Metallurgy. 31(3), 257-264.

8. Koseski, R. P., Suri, P., Earhardt, N. B., German, R. M., \& Kwon, Y. S. (2005). Microstructural evolution of injection molded gas and water atomised $316 \mathrm{~L}$ stainless steel powder during sintering", Material Science and Engineering A 290. 171-177.

9. Gulsoy, H. O., Ozbek, S., \& Baykara, T. (2007). Microstructural and mechanical properties of injection moulded gas and water atomised 17-4 PH stainless steel powder, Powder Metallurgy. 50:100106.

10. Subuki, I., Omar, M. A., Ismail M. H., \& Halim, Z. (2007). Injection Moulding of 316L Stainless Steel using Palm Stearin Based Binder" in Proc. Feb. 2007 AEESEAP. 27-30.

11. Omar, M. A., \& Subuki, I. (2002). Rapid Debinding of 316L Stainless Steel Injection Moulded Component Using Palm Based Biopolymer Binder" in Proc. April $20073^{\text {rd }}$ Colloquium on Materials, Minerals and Polymers. 196-198. 